\title{
Fire protective performance of intumescent paint and ablative elastomer used for high pressure hydrogen composite cylinder
}

\author{
D. QUANG DAO ${ }^{1,3}$, THOMAS ROGAUME ${ }^{1}$, JOCELYN LUCHE ${ }^{1}$, FRANCK RICHARD ${ }^{1}$, L. \\ BUSTAMANTE VALENCIA ${ }^{2}$ and SIDONIE RUBAN ${ }^{2}$ \\ ${ }^{1}$ Département Fluides, Thermiques, Combustion, \\ Institut Pprime, CNRS - Université de Poitiers - ENSMA, \\ 1 avenue Clément Ader, BP40109, F86961 Futuroscope Chasseneuil Cedex, France \\ ${ }^{2}$ Air Liquide, \\ Centre de Recherche Claude-Delorme, \\ 78350 Les Loges-en-Josas, France \\ ${ }^{3}$ Center of Research and Development, \\ Duy Tân University, \\ K7/25 Quang Trung, Da Nang, Vietnam
}

\begin{abstract}
The thermal degradation of epoxy resin/carbon fiber composites have been experimentally studied in ISO 5660 standard cone calorimeter. The influence of external heat fluxes on the reaction-to-fire properties of composite laminate is identified. Mass loss, time-to-ignition, specific mass loss rate, thermal response parameter and gasification heat were systematically measured and calculated. The four principal steps of the thermal degradation process of virgin composite are also analyzed and identified. In order to improve the reaction to fire of the composite for a safe hydrogen cylinder application, two insulating coatings (constituted by an intumescent paint or an ablative elastomer) have been applied on the exposure surface of composite. As a result, the thermal properties of composite (mass loss, time-to-ignition, SMLR peak amplitude and temperature at coating/composite interface) are improved significantly. Furthermore, the ablative elastomer represents a better fire protective performance than the intumescent paint one at low temperature. However, at high temperature conditions, the ablative layer is thermally broken and flaked away from the composite substrate, and so loses its protective performance. At low heat flux the intumescent paint shows slightly worse protective performance which becomes better than the ablative material at high heat flux conditions due to its very good bonding capacity to the composite surface.
\end{abstract}

KEYWORDS: epoxy resin, carbon fiber, composite, intumescent paint, ablative material, cone calorimeter.

\section{NOMENCLATURE LISTING}

\begin{tabular}{llll}
$c_{p}$ & specific heat capacity, $(\mathrm{kJ} / \mathrm{kg} \mathrm{K})$ & \multicolumn{2}{l}{ Greek } \\
$t_{i g}$ & ignition time $(\mathrm{s})$ & $\rho$ & density, $\left(\mathrm{kg} / \mathrm{m}^{3}\right)$ \\
$T_{i g}$ & ignition temperature $(\mathrm{K})$ & $\lambda$ & thermal conductivity, $(\mathrm{W} / \mathrm{m} \mathrm{K})$ \\
$T R P$ & thermal response parameter, $\left(\mathrm{kW} \mathrm{s}^{0.5} / \mathrm{m}^{2}\right)$ & $\alpha$ & thermal diffusivity $\left(\mathrm{m}^{2} / \mathrm{s}\right)$ \\
$P$ & thermal inertia, $\left(\mathrm{kW}^{2} \mathrm{~s} / \mathrm{m}^{4} \mathrm{~K}^{2}\right)$ & & \\
$L$ & heat of gasification, $(\mathrm{kJ} / \mathrm{g})$ & & \\
$C H F$ & critical heat flux, $\left(\mathrm{kW} / \mathrm{m}^{2}\right)$ & & \\
$S M L R$ & specific mass loss rate, $\left(\mathrm{g} / \mathrm{m}^{2} \mathrm{~s}\right)$ &
\end{tabular}

\section{INTRODUCTION}

Hydrogen is a very promising fuel that has been progressively explored for passenger vehicles. However, several technical and economic challenges (i.e. fuel storage, fuel cost, etc...) have to be resolved before it can be widely used. Different storage techniques are actually developed and used. Among them, high pressure cylinder is a traditional method commonly applied for a long time. Four gas cylinder types have been developed over time: first cylinders constituted of steel, then aluminum and more recently two composite types. The most advanced composite cylinder consists in type 4 (high molecular weight polymeric liner, normally reinforced with carbon fiber), while type 3 has a fully wrapped aluminum liner, and type 2 has a hoop wrapped metallic liner [1]. 
However, the use of such highly flammable materials (i.e. carbon/epoxy composite and/or thermoplastic liner) may induce a high failure risk of cylinder under accidental fire exposure due to their temperature dependent properties. The high pressure (usually from 34.5 to $70.0 \mathrm{MPa}$ ) in the hydrogen cylinder may result in a catastrophic burst and human damage [2]. Therefore, the careful studies of fire reaction properties of the polymer materials used in composite cylinders, as well as the solution to enhance their flame retardant properties are critical and indispensable for safe design.

Thermal degradation of fiber-reinforced epoxy resin composites is the subject of the major studies in literature not only in elementary scale tests (i.e. Thermogravimetric Analysis TGA, Differential Thermal Analysis DTA, or Differential Scanning Analysis DSC) [3-7] but also in small ones (i.e. ISO 5660 cone calorimeter) [8-19]. The last draws a wide attention in recent studies because of the better assessment of material behaviors in real fire scenarios. Several reaction-to-fire properties of fiber-reinforced epoxy resin composites have been measured such as: time-to-ignition, heat release rate $(H R R)$, amount and rate of mass loss, density and specific extinction area of smoke, gaseous emissions as well as limit oxygen index (LOI) [8-19]. It is found that different parameters as external heat flux, composite properties (nature of fiber, fiber content and fiber arrangement within composite, sample thickness) and fire environment condition, can have an influence on the thermal properties of composite.

To protect the composite against fire, a lot of fire retardant strategies can be applied such as: modification of the chemical nature of composite or use of an insulating protective coating. The ideal coatings should possess the following properties: non-flammability, low thermal conductivity, strong adhesion to the composite substrate, environmentally durable, wear resistant, light weight, thin and inexpensive [20]. Three major types of insulating coatings are classically used for composite substrates: flame retardant polymers, thermal barriers and intumescent coatings.

The first coatings inherently consist in fire resistant organic resins (e.g. phenolic, brominated or alkyd resins with a high loading of flame retardant filler) or inorganic materials (e.g. geopolymers). These polymers that are applied as a thin film on the composite surface can delay significantly the pyrolysis of composite materials [21-22]. The thermal barrier coatings include essentially mineral fiber or ceramic wool mats that are normally bonded to the composite substrate using a high-temperature adhesive. They provide excellent insulating properties and heat reflective ones that direct heat back towards the fire [20, 23-24]. The intumescent coatings subjected to high temperature provides the fire protection via an endothermic decomposition reaction process that causes the material to swell and foam into a highly porous, thick and thermally stable char layer [20, $25-27]$. This high void content of the thick char layer plays a role as a thermal barrier that prevents the composite from flame and heat, and so delays the thermal decomposition of material. Another type of insulating coatings is ablative materials that provide thermal protection by removing heat from the hot surface by spalling or melting [21]. In the ablation process, the high heat fluxes are dissipated by material through a series of endothermic processes that finally lead to the loss and consumption of the material itself [28]. The ablative materials are commonly used for the protection of polymer composites in high temperature applications, such as rocket nozzles and heat shields to re-entry spacecraft [20].

This study is a part of longer and broader research program studying the fire behaviors of different materials (composite laminate, thermoplastic liners and fire protective coatings) used in high pressure hydrogen composite cylinders. The fire reaction properties of the carbon fiber reinforced epoxy resin composite (59 vol\% of carbon fiber) were experimentally determined in an open cone calorimeter, such as: time-to-ignition, amount and rate of mass loss, thermal response parameter, ignition temperature, thermal inertia and heat of gasification. The influence of two commercial flame retardant coatings (i.e. intumescent paint and ablative elastomer) on the fire behaviors of composite laminate was also evaluated. The type of measurements permits a better selection of coating materials for composite cylinder application. 


\section{MATERIALS \& EXPERIMENTAL SETUP}

\section{Materials}

The commercial epoxy composites in pre-preg form (carbon fiber pre-impregnated in the epoxy resin) are used in this study. This consists in the unidirectional ply laminated composite (e.g. closely spaced parallel fibers). The material is in development for hydrogen storage cylinder applications, thus all detailed information about material as well as material preparation process is still confidential and cannot be presented in the present paper.

In general, the composite is constituted by an epoxy resin used with a hardener, without flame retardant addition and reinforced by carbon fibers. An elementary analysis of the virgin epoxy resin and the composite with $59 \mathrm{vol} \%$ carbon fibers $(\mathrm{CF})$ is investigated by coupling catharometry and ND-IR detection. In principle, a total combustion or pyrolysis of material sample is realized at about $1050^{\circ} \mathrm{C}$ under helium/oxygen or oxygen or helium atmosphere depending on the analysed elements. The gaseous products obtained are then separated in a chromatographic column and measured by different types of detectors, e.g. thermal conductivity detector or non-dispersive infrared detector (ND-IR). Different equipment is used to quantify these elements such as: CSA2003 Rosemount, Horiba EMGA 620 and Leco SC-144.

Table 1 presents the composition in mass fraction along with the analysis methods. The elementary analysis was repeated three times and the maximal absolute deviation for each element is $\pm 0.4 \mathrm{wt} \%$ The results showed that the epoxy resin and the composite contained essentially four major elements $\mathrm{C}, \mathrm{O}, \mathrm{H}$ and $\mathrm{N}$ representing respectively $99.6 \mathrm{wt} \%$ and $98.7 \mathrm{wt} \%$ of the total mass. The difference of 0.4 and $1.3 \mathrm{wt} \%$ in composition of the two materials may be due to the measure deviation or the presence of other compounds such as ash (minerals) or impurity trace in carbon fiber (sodium, metallic compounds, etc.). The presence of $\mathrm{N}$-element $(3.2 \mathrm{wt} \%)$ is related to the use of a reversible amine hardener. The addition of carbon fibers in the composites led to an increase of $\mathrm{C}$ and $\mathrm{N}$ atom amounts which may be due to the presence of the (-CN) chemical functions in the carbon fiber precursors during the fabrication of these carbon fiber/epoxy resin composites.

Table 1. Elementary mass fraction of the epoxy resin and the epoxy resin/carbon fiber composite.

\begin{tabular}{|l|c|c|c|}
\hline Element & Pure epoxy resin & Composite 59 vol\% CF & Measurement methods \\
\hline $\mathrm{C}$ & $70.6 \%$ & $84.6 \%$ & Catharometry by transformation $\mathrm{CO}_{2}$ \\
\hline $\mathrm{O}$ & $17.1 \%$ & $5.4 \%$ & ND-IR by transformation on $\mathrm{CO}$ \\
\hline $\mathrm{H}$ & $8.5 \%$ & $2.9 \%$ & Catharometry by transformation on $\mathrm{H}_{2} \mathrm{O}$ \\
\hline $\mathrm{N}$ & $3.2 \%$ & $5.4 \%$ & Catharometry by reduction on $\mathrm{N}_{2}$ \\
\hline Residue & $<0.1 \%$ & $<0.1 \%$ & ND-IR detection \\
\hline $\mathrm{Cl}$ & $0.1 \%$ & $390 \mathrm{ppm}$ & ND-IR detection \\
\hline $\mathrm{S}$ & $<10 \mathrm{ppm}$ & $<10 \mathrm{ppm}$ & Karl-Fischer \\
\hline Water & - & $0.3 \%$ & \\
\hline Total & $<99.6 \%$ & $<98.7 \%$ & \\
\hline
\end{tabular}

Some preliminary tests were performed to determine the main properties of the $59 \mathrm{vol} \% \mathrm{CF}$ composites such as: density, heat capacity, thermal conductivity and diffusivity at the ambient conditions (293 K and 1 atm). Details of these measurements can be found in [14]. And as a result, the composite density $(\rho)$ was $1472 \pm 20 \mathrm{~kg} / \mathrm{m}^{3}$ and specific heat capacity $\left(c_{p}\right)$ was $0.9 \mathrm{~kJ} / \mathrm{kg} \mathrm{K}$. The diffusivity $(\alpha)$ measured in the parallel and the transverse direction of the carbon fibers was equal to $2.75 \pm 0.10$ and $0.40 \pm 0.04 \mathrm{~mm}^{2} / \mathrm{s}$, respectively. In turn, the conductivity $(\lambda)$ was found to be $3.30 \pm 0.30 \mathrm{~W} / \mathrm{m} \mathrm{K}$ in the parallel direction and $0.48 \pm 0.05 \mathrm{~W} / \mathrm{m} \mathrm{K}$ in the transverse direction of carbon fibers.

Two commercial thermal insulating coatings named A and B that could be potentially used for the hydrogen high pressure composite cylinders, were evaluated in this study. The insulating coating A consisted in an intumescent paint, while the coating B was an ablative elastomer that contained the chemical elements as following: $\mathrm{C}, \mathrm{O}, \mathrm{H}, \mathrm{Si}, \mathrm{B}, \mathrm{Na}, \mathrm{Ca}, \mathrm{Fe}$ and Pt. These two protective materials are in the development especially for this project, so we cannot provide further information about their properties. 


\section{Experimental Setup}

The thermal degradation of tested samples was investigated in the ISO 5660 standard cone calorimeter developed by Fire Testing Technology Limited under well-ventilated conditions [30]. All details of the apparatus and the test procedure can be found elsewhere [14, 31-32].

The composite samples were $100 \pm 0.5 \mathrm{~mm}$ long $\times 100 \pm 0.5 \mathrm{~mm}$ wide $\times 10.1 \pm 1.5 \mathrm{~mm}$ thick and were exposed to the external heat fluxes from 10 up to $75 \mathrm{~kW} / \mathrm{m}^{2}$. The relative uncertainty of heat flux was about $\pm 5 \%$. The initial mass of composite sample was equal to $148.7 \pm 1.8 \mathrm{~g}$. Samples were placed on a standard metal holder with horizontal orientation on a bed of rock wool $\left(90 \mathrm{~kg} / \mathrm{m}^{3}\right.$ of density and $4 \mathrm{~cm}$ of thickness), which insulate the back side of sample to minimize the heat loss effect, as described in the ISO 5660 standard [30]. On the other hand, aluminum foil also wrapped around the edges and the back of sample to prevent the aqueous polymer dripping. Tests were carried out under air atmosphere with a piloted ignition (spark ignition plug) positioned above the sample surface, and repeated at least three times to ensure the result reproducibility.

The intumescent solvent-borne alkyd paint A was manually coated on the surface of composite sample by a $1 \mathrm{~mm}$-thickness layer. In order to ensure a good repartition of the intumescent paint on the composite surface, the composite samples were placed side by side so that they all were simultaneously coated at the same time. The insulating coating was respectively implemented by three different layers: an anticorrosion protection alkyd paint serving as an adhesion layer, a solvent-phase intumescent paint providing the thermal stability performance, and a solvent-phase satin paint for finishing the intumescent system. The averaged mass of the intumescent layer was equal to $5.2 \pm 0.2 \mathrm{~g}$ that corresponds to $3.3 \mathrm{wt} \%$ of the total mass of coating/composite sample.

The ablative coating $\mathrm{B}$ was prepared in rigid plate of $7.6 \pm 0.3 \mathrm{~mm}$ thickness. The initial mass of the ablative layer was about $36.6 \pm 0.2 \mathrm{~g}$ (corresponds to $19.7 \mathrm{wt} \%$ of the total mass) and the volumetric mass was equal to $0.46 \mathrm{~g} / \mathrm{cm}^{3}$. The bonding of the thermal protection layer on the composite surface was performed by a $0.5 \mathrm{~mm}$ - thickness elastomer adhesive.

The temperature profiles at the exposed composite surface and at the interface of composite and insulating layers were measured by using a $1 \mathrm{~mm}$-diameter K-type thermocouple (Fig.1). As can be seen in Fig. 1, the thermocouple was located at the sample center, and mounted from the bottom to the top surface (or to the interface of materials) by a $1 \mathrm{~mm}$ - diameter hole. The temperature measurements were repeated three times for each experimental configuration with a maximum absolute deviation of $\pm 20 \mathrm{~K}$.

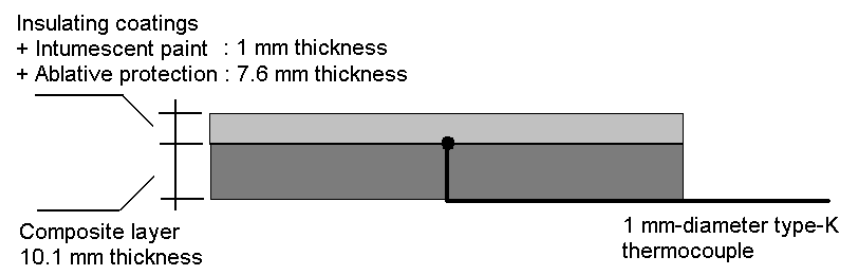

Fig.1. Thermocouple setup

\section{RESULTS AND DISCUSSIONS}

\section{Thermal degradation of epoxy resin/carbon fiber composite}

Several parameters that characterize the thermal degradation of epoxy resin/carbon fiber composite such as: piloted ignition time and temperature $\left(t_{i g}\right.$ and $\left.T_{i g}\right)$, mass loss, specific mass loss rate $(S M L R)$, critical heat flux $(C H F)$, thermal response parameter $(T R P)$, thermal inertia $(P)$ and heat of gasification $(L)$, are systematically determined in this study. These measurements in the cone calorimeter test scale allow a better understanding of the behaviors of composite material in fire. Some parameters such as TRP, $P, L$ and $T_{i g}$ are calculated from $\rho, c_{p}, k$, external heat flux and $t_{i g}$. The details of the experimental measurements as well as the calculation methods of the parameters are presented in a previous contribution [14]. 
Figs. 2 represents the transient evolution of specific mass loss rate $(S M L R)$ of 59 vol\% carbon fiber composite (without coating) exposed to $40 \mathrm{~kW} / \mathrm{m}^{2}$ (Fig. 2A) and to different external heat fluxes from the critical heat flux $\left(14 \mathrm{~kW} / \mathrm{m}^{2}\right)$ up to $75 \mathrm{~kW} / \mathrm{m}^{2}$ (Fig. $2 \mathrm{~B}$ ).

The analysis of the decomposition step shows that the thermal degradation and combustion of epoxy resin/carbon fiber takes place in four phases (Fig. 2A): (1) the thermal cracking of epoxy resin to form the low molecular weight gaseous species that leads to the flaming ignition, and char forming, (2) the acceleration of epoxy resin degradation jointly with the formation of monomer solvent that is displayed by the first peak in Fig. 2., (3) the combustion of the monomer solvent and degradation of remained epoxy resin that is represented by the second higher SMLR peak, and (4) the oxidation of carbon char and carbon fiber decomposition [14].
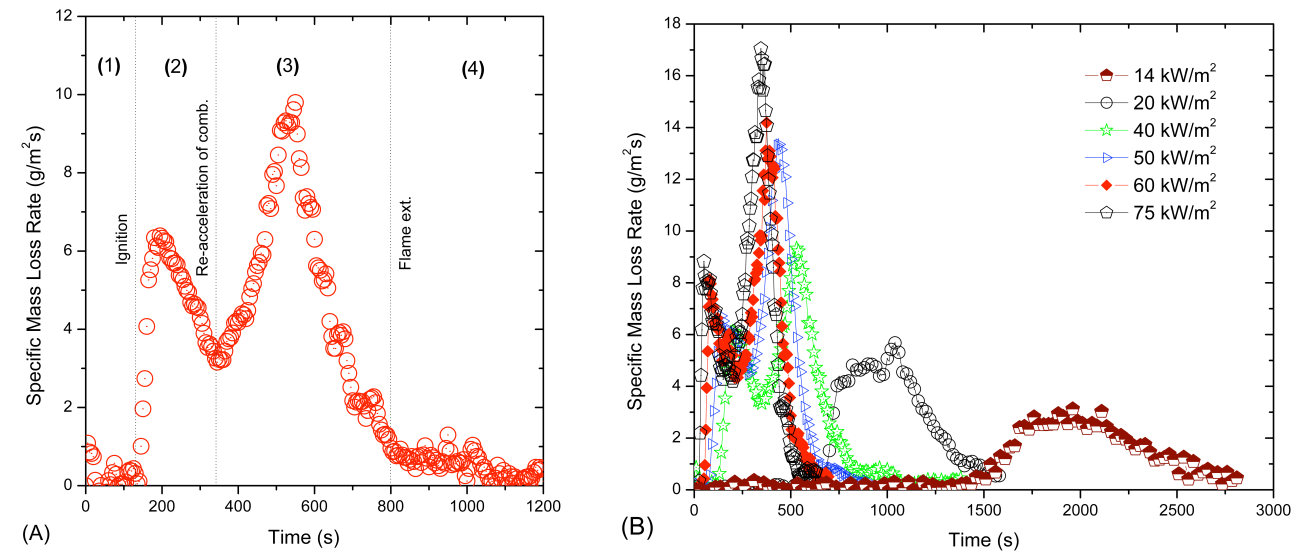

Fig. 2. Evolution of specific mass loss rate $(S M L R)$ of composite alone subjected to (A) $40 \mathrm{~kW} / \mathrm{m}^{2}$; (B) from 14 to $75 \mathrm{~kW} / \mathrm{m}^{2}$

As can be seen in Fig. 2B, the SMLR peak amplitudes increase and SMLR peak widths decrease strongly with an increase of the external heat flux. For example, the $S M L R$ peak amplitude increases from about 2.6 to $17 \mathrm{~g} / \mathrm{m}^{2} \mathrm{~s}$ when the heat flux increases from 14 to $75 \mathrm{~kW} / \mathrm{m}^{2}$, respectively. Moreover, at the heat flux of $14 \mathrm{~kW} / \mathrm{m}^{2}$, the thermal decomposition of composite occurs in a period of about $1300 \mathrm{~s}$ (from about 1500 to $2800 \mathrm{~s}$ ), while at $75 \mathrm{~kW} / \mathrm{m}^{2}$ the thermal decomposition takes place in about $500 \mathrm{~s}$ (from about 30 to $530 \mathrm{~s}$ ). This observation shows that the external heat flux increase accelerates the degradation of composite and decrease its thermal resistance.

Table 2 resumes the characteristic parameters of the thermal degradation of 59 vol\% carbon fiber composite. As can be seen in table 2, the ignition temperature of epoxy resin/carbon fiber composite alone is about $573 \mathrm{~K}$ that is generally smaller than pure epoxy resin reported in literature (i.e. $650-800 \mathrm{~K}$ ) [32, 33]. This may be due to the presence of carbon fiber in composite. Indeed, the higher thermal conductivity of carbon fiber compared to the one of epoxy resin leads to a higher thermal dissipation of the composite. When the composite is exposed to fire, the heat transfer within material is faster, a thicker material layer is heated, and so less heat energy is needed to release a sufficient amount of flammable gases for the flaming ignition.

Moreover, the critical heat flux $(\mathrm{CHF})$ of the epoxy resin/carbon fiber composite seems to be in the same range of value with the one of the pure epoxy resin and the epoxy resin/glass fiber composite (i.e. 14 $\mathrm{kW} / \mathrm{m}^{2}$ as compared to $13-20$ and $10-15 \mathrm{~kW} / \mathrm{m}^{2}$, respectively). When the composite material is exposed to fire, it is the epoxy resin that is firstly decomposed, ignited and burnt. So, the similar inflammability properties of these materials may be due to the presence of the similar epoxy resin.

The thermal response parameter (TRP) is another critical parameter that allows estimating the material resistance to generate a combustible mixture. The presence of carbon fiber induces a lower TRP value of epoxy/carbon composite as compared to the epoxy resin and epoxy/glass composite, i.e. $370 \mathrm{~kW} \mathrm{~s} / \mathrm{m}^{2}$ as compared to 457 and $388-540 \mathrm{~kW} \mathrm{~s} \mathrm{~s}^{0.5} / \mathrm{m}^{2}$, respectively. The same trends can be observed when the thermal inertia and the gasification heat of composite are compared to the one of epoxy resin. In fact, the $P$ 
value of the composite is equal to $2.25 \mathrm{~kW}^{2} \mathrm{~s} / \mathrm{m}^{4} \mathrm{~K}^{2}$ as compared to $0.38 \mathrm{~kW}^{2} \mathrm{~s} / \mathrm{m}^{4} \mathrm{~K}^{2}$ for the epoxy resin. And the gasification heat of the composite is about $16 \mathrm{~kJ} / \mathrm{g}$ that is greater than the one of the epoxy resin (i.e. $2.4 \mathrm{~kJ} / \mathrm{g}$ ).

Table 2. Characteristic parameters of the thermal degradation of epoxy resin/carbon fiber composite

\begin{tabular}{|l|c|c|c|}
\hline \multicolumn{1}{|c|}{ Thermal parameters } & $\begin{array}{c}\text { This } \\
\text { work }\end{array}$ & $\begin{array}{c}\text { Epoxy resin } \\
{[\mathbf{3 2}, \mathbf{3 3}]}\end{array}$ & $\begin{array}{c}\text { Epoxy resin / } \\
\text { glass fiber [32] }\end{array}$ \\
\hline Piloted ignition temperature $T_{i g}, \mathrm{~K}$ & 575 & $650-800$ & - \\
\hline Critical heat flux $C H F, \mathrm{~kW} / \mathrm{m}^{2}$ & 14 & $13-20$ & $10-15$ \\
\hline Thermal response parameter $T R P, \mathrm{~kW} \mathrm{~s}{ }^{0.5} / \mathrm{m}^{2}$ & 370 & 457 & $388-540$ \\
\hline Thermal inertia $P, \mathrm{~kW} \mathrm{~kW}^{2} \mathrm{~s} / \mathrm{m}^{4} \mathrm{~K}^{2}$ & 2.25 & 0.38 & - \\
\hline Heat of gasification $L, \mathrm{~kJ} / \mathrm{g}$ & 16 & 2.4 & - \\
\hline
\end{tabular}

So, it can be found that the presence of carbon fiber causes a worse thermal resistance of material in fire because of its higher thermal conductivity. Then, the choice of an optimal carbon fiber fraction is critical to maintain simultaneously good mechanical and thermal resistance properties of carbon fiber reinforced epoxy resin composite.

\section{Thermal degradation of the insulating coating/composite sample}

To enhance the flame retardant properties of carbon fiber reinforced epoxy resin composite, two different fire protective surface coatings are evaluated in this study. An intumescent paint (named Coating A) and an ablative elastomer (named Coating B) have been used. The whole system insulating coating/composite was subjected to the irradiant source of cone calorimeter. The incident heat flux is varied from 20 to $75 \mathrm{~kW} / \mathrm{m}^{2}$ in order to evaluate the protective performance of coatings.

Fig. 3 displays the evolution of mass loss level (wt\%) of the coating/composite samples at different heat fluxes from 30 to $75 \mathrm{~kW} / \mathrm{m}^{2}$. The result of insulating coating/composite samples obtained at the heat flux of $75 \mathrm{~kW} / \mathrm{m}^{2}$ is also compared with the one of the virgin composite in the same condition.

As can be seen in Fig. 3A, the thermal degradation of the coating A/composite occurs principally in three phases. Firstly, a very slow degradation with a slight mass loss of about $2 \mathrm{wt} \%$ is observed at all heat flux conditions. This is corresponding to thermal decomposition of the intumescent paint (coating A). Then, a more rapid mass loss that consists in the thermal degradation and the combustion of the composite is found. Depending on the heat flux condition from 30 to $75 \mathrm{~kW} / \mathrm{m}^{2}$, the mass loss level of this step increases from about 14 to $28 \mathrm{wt} \%$, respectively. Finally, a new mass loss that represents the oxidation and decomposition of char compounds is recognized in the third phase. On the other hand, the intumescent paint (coating A) shows clearly its positive fire protective performance. Indeed, at the highest heat flux of our experimental condition (i.e. $75 \mathrm{~kW} / \mathrm{m}^{2}$ ) the mass loss evolution of the coating A/composite sample is considerably shifted to the right hand side of fig. $3 \mathrm{~A}$ as compared to the one of the virgin composite. In order to obtain the same mass loss level of $28 \mathrm{wt} \%$, the thermal degradation of the coating $\mathrm{A} /$ composite occurs in a period of about $1200 \mathrm{~s}$, while the one of the virgin composite takes place in about $600 \mathrm{~s}$.

The same phenomenon of a three-step degradation process can be remarked with the use of the ablative elastomer (coating B) as insulating coating (Fig. 3B). The first step of elastomer degradation induces a loss of $6 \mathrm{wt} \%$ of total sample mass. It is highlighted that the initial mass of the elastomer coating layer corresponds to $19.7 \mathrm{wt} \%$. It means that a remarkable amount of char is still remained at the exposed surface to protect the composite substrate from the external heat. The second step induces a mass loss level of about $26 \mathrm{wt} \%$ for all heat flux conditions from 30 to $75 \mathrm{~kW} / \mathrm{m}^{2}$. The last step presents systematically whatever the heat flux chosen a slight mass loss of samples. Moreover, it is seen in Fig. 3B that the ablative material (coating B) seems to have a better protective performance than the intumescent paint (coating A). Indeed, in order to obtain a mass loss level of $28 \mathrm{wt} \%$ at the heat flux of $75 \mathrm{~kW} / \mathrm{m}^{2}$, the coating $\mathrm{B} /$ composite sample is decomposed in a period of time of about $2000 \mathrm{~s}$, while the thermal degradation of coating $\mathrm{A}$ /composite is occurred in a period of $1200 \mathrm{~s}$ as mentioned above. In all cases of insulating coating used, it is noted that no flaming ignition is observed at the lowest heat flux condition, i.e. under $30 \mathrm{~kW} / \mathrm{m}^{2}$. 

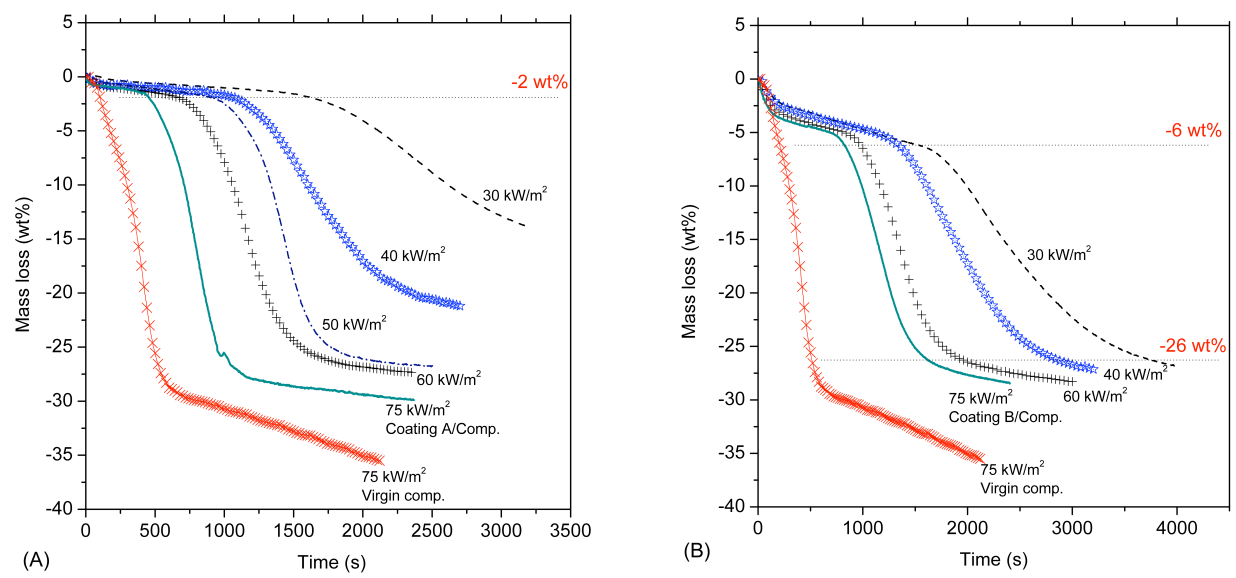

Fig. 3. Evolution of mass loss level at different external heat fluxes from 30 to $75 \mathrm{~kW} / \mathrm{m}^{2}$ for (A) Coating $\mathrm{A} /$ composite and (B) Coating B/composite

Depending on the fire protective performance of insulating coating used, the piloted ignition time, the specific mass loss rate (SMLR) of composite and the temperature at coating/composite interface are quite different. The following part of this paper compares these properties at different incident heat fluxes from 30 to $75 \mathrm{~kW} / \mathrm{m}^{2}$ for the two types of protective coating.

Fig. 4. displays the piloted ignition time of carbon fiber reinforced epoxy resin composite at four irradiant heat fluxes from 30 to $75 \mathrm{~kW} / \mathrm{m}^{2}$ under the thermal protection of the intumescent paint (coating A) and the ablative elastomer (coating B). The ignition time is experimentally observed as the moment of second reinflammation from the beginning of cone calorimeter test. The ignition time of protected composite will be defined more detailed in the later section of the manuscript. This is considered as the moment at which the insulating coating loses its protective performance. So, it is used in this study to compare the protective performance of insulating coatings.

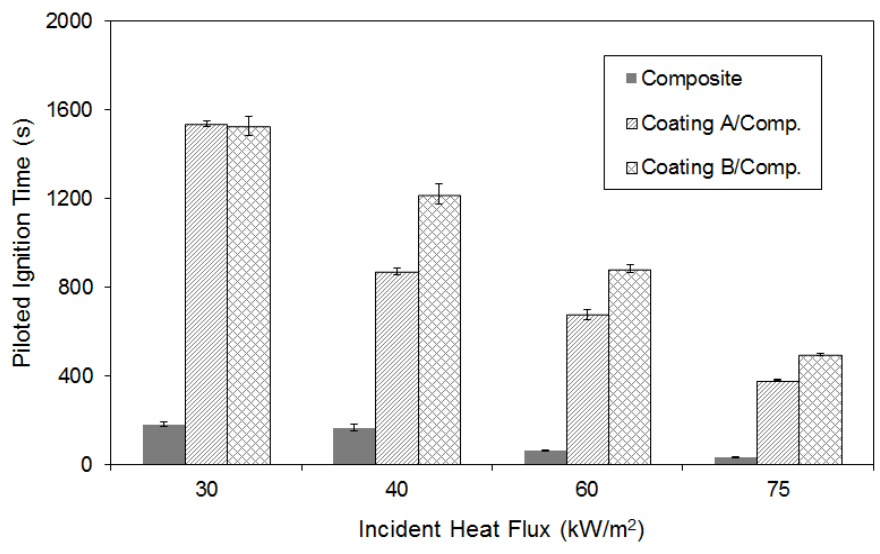

Fig. 4. Influence of coating type on the piloted ignition time of epoxy resin/carbon fiber composite

As can be seen in Fig. 4, the presence of an insulating coating layer enhances strongly the thermal resistance of composite in fire. In fact, at the lowest external heat flux of $30 \mathrm{~kW} / \mathrm{m}^{2}$ the piloted ignition time increases from $180 \pm 10 \mathrm{~s}$ for the virgin composite to $1540 \pm 11 \mathrm{~s}$ and $1530 \pm 40 \mathrm{~s}$ for the coating $\mathrm{A} /$ composite and coating $\mathrm{B} /$ composite, respectively. At $75 \mathrm{~kW} / \mathrm{m}^{2}$, the ignition time of virgin composite is $33 \pm 3 \mathrm{~s}$, while the one of coating $\mathrm{A} /$ composite and coating $\mathrm{B} /$ composite is respectively $382 \pm 2 \mathrm{~s}$ and $496 \pm$ $5 \mathrm{~s}$, respectively. For all external heat fluxes, it is observed that the ablative elastomer (coating B) represents a better fire protective performance than the intumescent paint (coating A). For example at an external heat flux of $40 \mathrm{~kW} / \mathrm{m}^{2}$, the piloted ignition time is $870 \pm 14 \mathrm{~s}$ in the case of the coating 
$\mathrm{A} /$ composite sample, while it is about $1220 \pm 50 \mathrm{~s}$ in the case of coating B/composite. This difference in the ignition time may be due to the considerable difference of coating layer thickness, i.e. $1 \mathrm{~mm}$ for the intumescent paint as compared to $7.6 \mathrm{~mm}$ of the ablative elastomer.

On the other hand, it is observed that the critical heat flux $(\mathrm{CHF})$ of composite is also enhanced considerably in using the fire protective coatings. As reported in Table 2, the minimum heat flux at which the virgin composite subjected to fire is ignited is equal to $14 \mathrm{~kW} / \mathrm{m}^{2}$. Under the protection of both insulating coatings, the $C H F$ is increased to about $30 \mathrm{~kW} / \mathrm{m}^{2}$. No ignition of composite is experimentally observed at the lowest heat fluxes studied (i.e. under $30 \mathrm{~kW} / \mathrm{m}^{2}$ ).

Figs. 5 show the evolutions of specific mass loss rate of virgin composite and the coating/composite systems exposed to different incident heat fluxes from 30 to $75 \mathrm{~kW} / \mathrm{m}^{2}$.
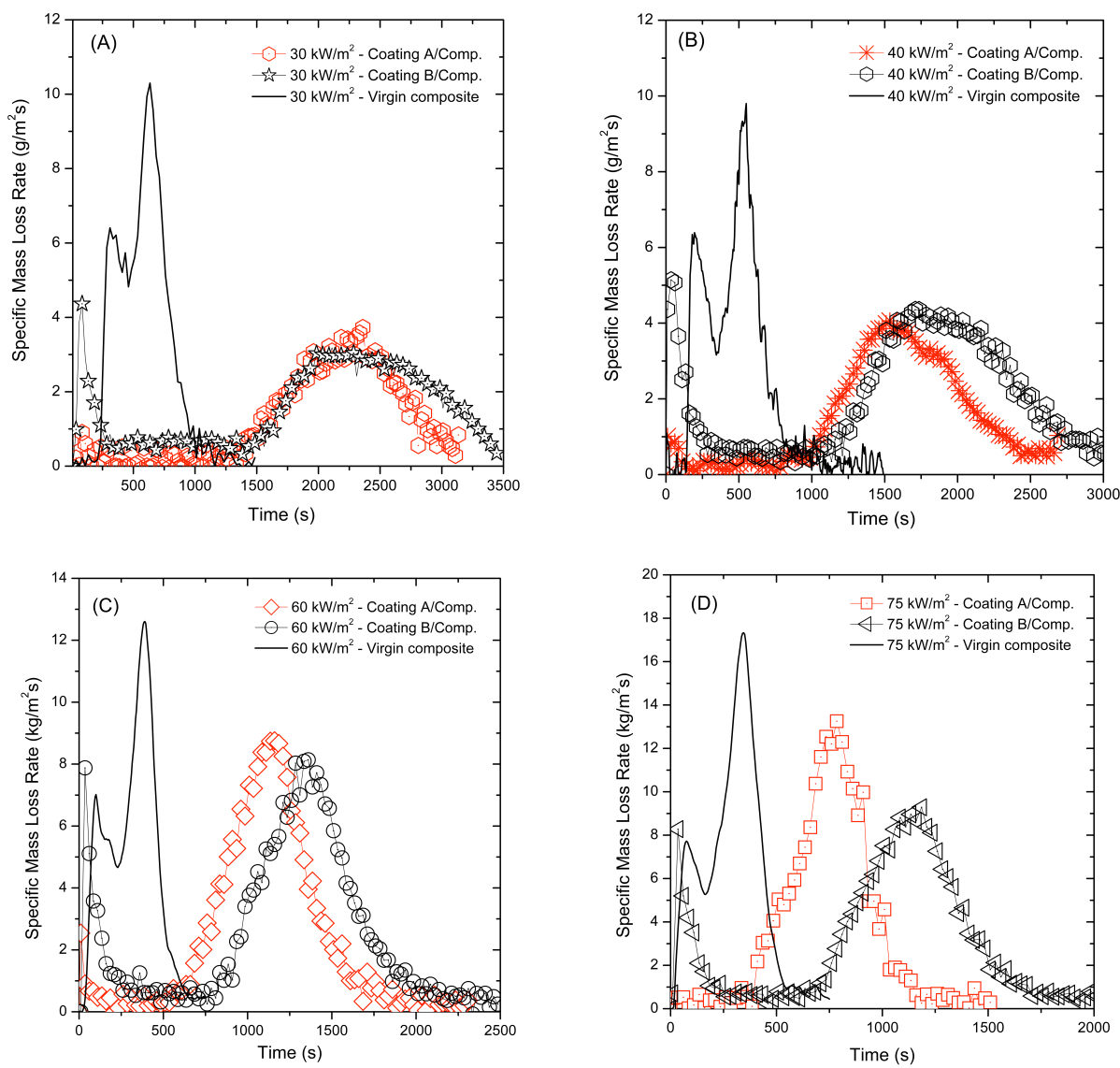

Fig. 5. Influence of coating materials on the evolution of specific mass loss rate $(S M L R)$ at different incident heat fluxes: (A) $30 \mathrm{~kW} / \mathrm{m}^{2}$; (B) $40 \mathrm{~kW} / \mathrm{m}^{2}$; (C) $60 \mathrm{~kW} / \mathrm{m}^{2}$ and (D) $75 \mathrm{~kW} / \mathrm{m}^{2}$

As observed above, the adding of the coating layer delays dramatically the thermal degradation of composite at all the external heat fluxes. The second peak in Figs. 5 that represents the thermal degradation of the protected composite are significantly shifted to the right hand side of the picture. The ignition time of the composite is increased in presence of insulation coating layer as reported in Fig. 4. For example, at the external heat flux of $60 \mathrm{~kW} / \mathrm{m}^{2}$ (Fig. 5C), the ignition time is increased from $61 \pm 2 \mathrm{~s}$ for the virgin composite to $680 \pm 22$ and $880 \pm 18 \mathrm{~s}$ for the composite under protection of the intumescent paint (coating A) and the ablative elastomer (coating B), respectively.

In order to evaluate the fire protective performance of each coating along the test, the temperature at the interface of coating layer and composite one was measured at different external heat fluxes. The Fig. 6 presents the results obtained at the intermediate heat flux of our experimental configurations, i.e. 40, 60 $\mathrm{kW} / \mathrm{m}^{2}$. The results presented are representative for all the ones obtained with our experimental 
configurations. The Fig. 6 shows also a comparison of the results obtained from the coating/composite samples with the one of virgin composite subjected to $40 \mathrm{~kW} / \mathrm{m}^{2}$. As a result, all the insulating coatings tested in this study show a positive improvement of heat shields. A maximum decreasing of the temperature at coating/composite interface up to about $200 \mathrm{~K}$ is recorded along the cone calorimeter test.

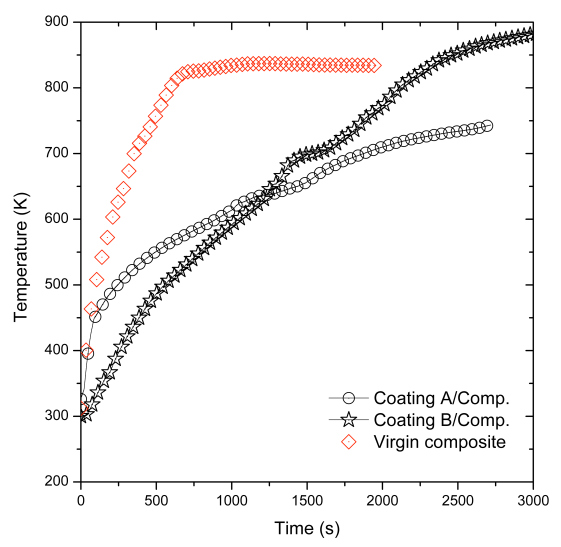

Fig. 6. Evolution of temperature at coating layer/composite interface for the heat flux of $40 \mathrm{~kW} / \mathrm{m}^{2}$

(A)

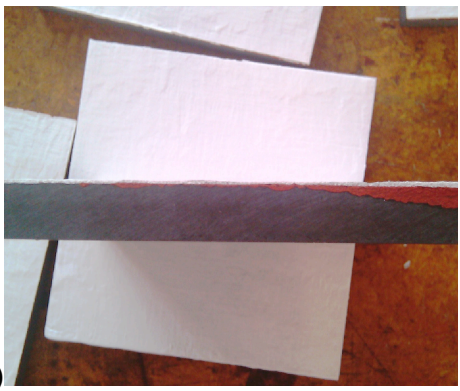

(B)

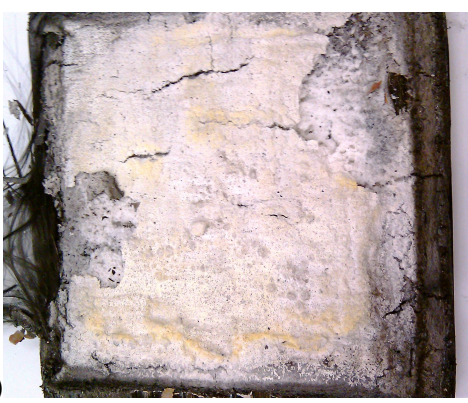

(C)

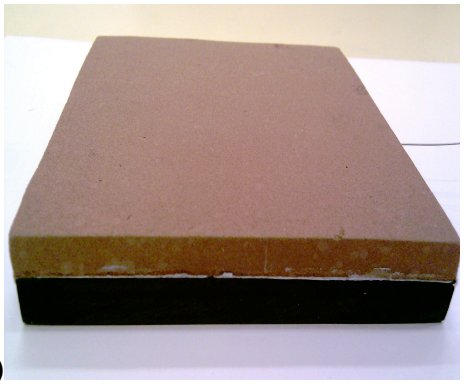

(D)

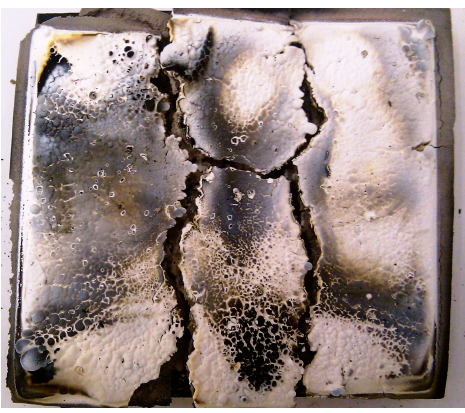

Fig. 7. Photograph of (A) Coating A/composite before exposure; (B) Coating A/composite after exposure at $75 \mathrm{~kW} / \mathrm{m}^{2}$; and (C) Coating B/composite before exposure; (D) Coating B/composite after exposure at 75 $\mathrm{kW} / \mathrm{m}^{2}$

Furthermore, the fire protective performance of the two coatings is quite different along the test. As can be seen in Fig. 6, the coating B (i.e. ablative elastomer) shows a better thermal resistance at the beginning of cone calorimeter test in comparison to the coating A (i.e. intumescent paint). For example, the temperature at the coating $\mathrm{B} /$ composite interface is clearly lower than the one of coating $\mathrm{A} /$ composite in the first 1000 seconds when the samples are exposed to $40 \mathrm{~kW} / \mathrm{m}^{2}$ (Fig. 6A). However at the later period of time, an inverse observation is found with a higher temperature at the interface of the coating $\mathrm{B} /$ composite sample. This can be explained by the breaking and flaking of ablative coating layer (coating B) away the composite surface that favors the heat transfers from the cone calorimeter into the composite layer (Fig. 7D). And this leads to the raising of temperature measured at the interface. At the same condition of heat flux the porous 
char layer formed from the degradation processes of intumescent paint (coating A) still retains its structure, and no cracking phenomenon is observed in this case (Fig. 7B). For that reason, a low temperature is maintained at the composite layer under the protection of coating $\mathrm{A}$.

Table 3 resumes the thermal properties of the epoxy resin/carbon fiber composite and under the thermal protection of intumescent paint (coating A) and the ablative elastomer (coating B). The second column represents the difference of ignition time that is calculated as the difference between the piloted ignition time of the virgin composite and the one of the composite with the insulating coatings. The third column compares the temperature at the insulating coating/composite interface that is determined at the time of 300 $\mathrm{s}$ and for the highest external heat flux in our experimental conditions, i.e. $75 \mathrm{~kW} / \mathrm{m}^{2}$. The time of $300 \mathrm{~s}$ is chosen because it is found in our previous study that the composite cylinder without fire protective coating in bonfire tests still remains its mechanical resistance with the high pressure of gases within the cylinder during this period of time [34]. And the last column presents the peak amplitude of specific mass loss rate measured at $75 \mathrm{~kW} / \mathrm{m}^{2}$.

Table 3. Resume of thermal properties of epoxy resin/carbon fiber composite with different fire protective insulating (heat flux of $75 \mathrm{~kW} / \mathrm{m}^{2}$ and time of first $300 \mathrm{~s}$ )

\begin{tabular}{|c|c|c|c|}
\hline Sample & $\begin{array}{c}\text { Difference of ignition } \\
\left.\text { time (at } 75 \mathrm{~kW} / \mathrm{m}^{2}\right)\end{array}$ & $\begin{array}{c}\text { Interface } \\
\text { temperature at } 300 \mathrm{~s}\end{array}$ & $\begin{array}{c}\text { Peak of } S M L R \text { (at } \\
\left.75 \mathrm{~kW} / \mathrm{m}^{2}\right)\end{array}$ \\
\hline Virgin composite & - & $575 \mathrm{~K}$ & $17 \mathrm{~g} / \mathrm{m}^{2} \mathrm{~s}$ \\
\hline Coating A/composite & $360 \mathrm{~s}$ & $555 \mathrm{~K}$ & $14 \mathrm{~g} / \mathrm{m}^{2} \mathrm{~s}$ \\
\hline Coating B/composite & $420 \mathrm{~s}$ & $515 \mathrm{~K}$ & $9 \mathrm{~g} / \mathrm{m}^{2} \mathrm{~s}$ \\
\hline
\end{tabular}

As can be seen in table 3, the presence of both insulating coatings permits to improve significantly the fire resistance of the composite material. For example, the piloted ignition time of composite with the coating A is about $360 \mathrm{~s}$ longer than the one of virgin composite. And the interface temperature and the SMLR peak of coating $\mathrm{A} /$ composite sample are all lower than the ones of virgin composite, i.e. $555 \mathrm{~K}$ compared to $575 \mathrm{~K}$, and $14 \mathrm{~g} / \mathrm{m}^{2} \mathrm{~s}$ as compared to $17 \mathrm{~g} / \mathrm{m}^{2} \mathrm{~s}$, respectively. The same trends are observed for the case of the coating B.

Moreover, it is also found that the ablative elastomer (coating B) provides the better fire protective performance compared to the intumescent paint (coating A). Indeed, the difference of ignition time is clearly increased from $360 \mathrm{~s}$ up to $420 \mathrm{~s}$ when the coating A and coating B are used respectively. Similarly, the temperature at interface and the $S M L R$ peak amplitude of the coating $\mathrm{B} /$ composite sample are all lower than the ones of coating A/composite, i.e. $515 \mathrm{~K}$ compared to $555 \mathrm{~K}$ and $9 \mathrm{~g} / \mathrm{m}^{2} \mathrm{~s}$ compared to $14 \mathrm{~g} / \mathrm{m}^{2} \mathrm{~s}$, respectively.

So, the ablative elastomer (coating B) represents generally a better fire protective performance than the intumescent paint (coating A). This is due to the higher thickness of ablative layer (i.e. $7.6 \mathrm{~mm}$ ) as compared to the intumescent paint $($ i.e. $1 \mathrm{~mm}$ ). On the other hand, it is important to highlight that the adhesion of the ablative elastomer to the composite substrate seems to be worse than the one of the intumescent paint (Figs. 7). Indeed, at the high temperature conditions, the ablative coating layer begins to be broken and flaked away the composite surface while the intumescent foam char layer is still bonded with the composite substrate. This consists in a very important factor that needs to be considered in choosing the insulating coating for composite cylinder.

It is important to mention that the results obtained in this study are only validated for the specimens oriented horizontally in cone calorimeter. In the case of vertical orientation, the fire reaction properties of material could be different. This is due to the fact that the thermal environment, dominate heat transfer mode, air entrainment and the fire plume direction associated with the samples oriented vertically and horizontally are quite different [35].

\section{Analysis of the thermal degradation steps}

Fig. 8 represents the typical evolution of specific mass loss rate $(S M L R)$ of protective coating/composite systems and the one of the virgin composite subjected to an incident heat flux of $60 \mathrm{~kW} / \mathrm{m}^{2}$. The results obtained for this particular condition are representative of the others. 
Generally, the thermal degradation of the whole coating/composite system took place in three principal phases: the thermal degradation of coating material, the thermal degradation of the composite and the oxidation and the decomposition of char. The first step of coating decomposition is different depending on the chemical nature of coatings as described following:

- For the thermal degradation of the intumescent paint (coating A), the intumescent material undergoes an endothermic decomposition reaction process at elevated temperature that causes the material swelling and foaming into a highly porous, thick and thermally stable char layer. The char layer thickness is increased from the $1 \mathrm{~mm}$ initially to about $10 \mathrm{~mm}$ finally. This plays a role of a thermal barrier that prevents the heat transfer and the transport of ambient oxygen from external sources into the composite layer, and reversely the release of volatile compounds from composite to the exterior. This phenomenon enhances the fire resistance of composite. However, when the samples continue to be heated, this char layer is oxidized and destroyed. This allows the transport of the oxygen and the volatile gases in two opposite senses and then this leads to the flaming ignition of the composite.

- For the thermal degradation of the ablator elastomer (coating B), the gaseous products are released, ignited and burnt in leaving a dense and white carbonaceous char. The hot gaseous products resulted from the ablative material decomposition diffuse through the char to the surface. During this diffusion, they absorb energy from the char, and continue to react undergoing further decomposition. This allows blocking the incoming convective heat flux and keeps the surface temperature at certain range, so prevents the degradation of composite substrate. It is highlighted that the char layer thickness is unchanged during the ablator decomposition process. When the carbonaceous char continues to absorb heat, it reaches the temperature in which it oxidizes and is mechanically broken and flaked from the composite surface. This favors the ignition of the composite. And the flame of composite combustion is initially observed at the broken position on char layer.

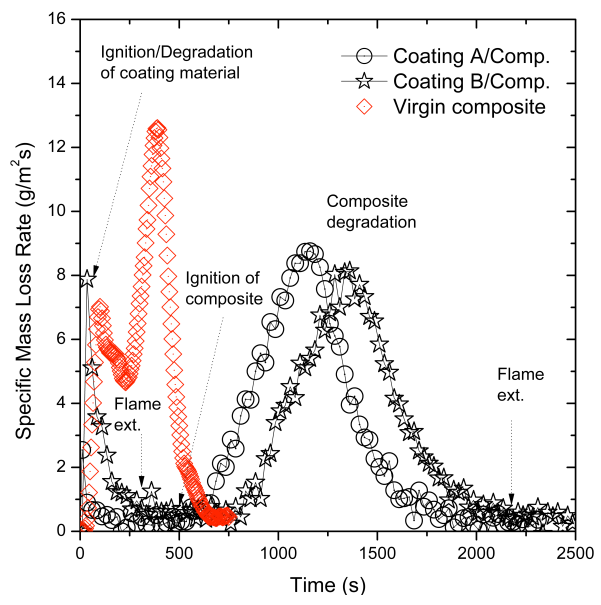

Fig. 8. Typical evolution of specific mass loss rate $(S M L R)$ of protective coating/composite system and of the virgin composite subjected to an incident heat flux of $60 \mathrm{~kW} / \mathrm{m}^{2}$

- In the second step, the epoxy resin/carbon fiber composite is ignited and burnt in only one single phase as presented in Fig. 8. The thermal degradation of the composite is accelerated with a strong increasing of $S M L R$ to reach a maximum value. Then, the specific rate of mass loss decreases rapidly until the flame extinction. Furthermore, the thermal degradation of the virgin composite at the same heat flux condition occurs in two distinguished steps represented by two different peaks (Fig. 3). So, the degradation of the composite with or without the presence of coating layer is quite different. This may be due to the thermal shield of coating char layer that prevents the second inflammation of the composite. And the protective performance of coating material is mainly influenced by the thickness of coating layer. The thickness of coating B layer is higher than the 
one of coating A, i.e. $7.6 \mathrm{~mm}$ as compared to $1 \mathrm{~mm}$ respectively. So, the coating B induces a higher ignition time, and a lower SMLR peak amplitude than the coating A.

And in the last steps of thermal degradation, the carbonaceous char layer resulted from the coating degradation as well as the residue of epoxy resin is slightly decomposed and oxidized. In this step, the temperature at the insulating coating/composite interface is sufficiently high (from 875 to $975 \mathrm{~K}$, Fig. 6B) so that the carbon fiber begins to be oxidized slowly.

\section{CONCLUSIONS}

This study has contributed to the evaluation the reaction-to-fire properties of the carbon fiber reinforced epoxy resin composite. The fire protective performance of the intumescent paint (coating A) and the charring ablative elastomer (coating B) used for high pressure hydrogen composite cylinder has been also tested. The mass loss, the piloted ignition time, the specific mass loss rate $(S M L R)$ and the temperature at the coating/composite interface for the virgin composite and the coating/composite samples were systematically recorded and compared. The conclusion is multiple:

- By comparing the thermal properties of pure epoxy resin, it is found that the presence of carbon fiber causes a worse thermal resistance of epoxy resin/carbon fiber composite. All the thermal properties of composite such as the ignition time, the thermal response parameter, the gasification heat, etc. are lower than the ones of pure epoxy resin. So, in order to balance a good mechanical property and thermal resistance of the high pressure composite cylinder, the choice of appropriate carbon fiber content within the composite is critical factor.

- Both the intumescent paint and the ablative elastomer ensure a good fire protective performance in a minimum of the first $300 \mathrm{~s}$ of exposure to radiant heat flux from cone calorimeter. No flaming ignition of the protected composite is experimentally observed in this range of time. In general, the ablative elastomer (coating B) represents a better protective performance than the intumescent paint (coating A) at low temperature conditions.

- However, the charring ablator (coating B) is broken and then flaked from the insulating layer at high temperature. This causes the loss of thermal protective performance of the ablative coating, and so leads to the thermal damage of the composite. Reversely, the intumescent paint is well bonded to the composite surface, thus this ensures its desired thermal protection during all the fire exposure of sample. So the choice of adhesive material and the bonding method is also an important factor.

The results obtained contribute to better understanding the reaction-to-fire properties of the carbon fiber reinforced epoxy resin composite used for the high pressure hydrogen composite cylinder, as well as to an appropriate choice of a fire protective coating to enhance the thermal resistance of this kind of material.

\section{ACKNOWLEDGEMENTS}

This work pertains to the French Government program "Investissements d'Avenir" (LABEX INTERACTIFS, reference ANR-11-LABX-0017-01)

\section{REFERENCES}

[1] Barthélémy, H., (2006) Ignition of a Composite Cylinder with Plastic Liner. Journal of ASTM International 3(5), http://dx.doi.org/10.1520/JAI13531

[2] Zheng, J., Liu, X., Xu, P., Liu, P., Zhao, Y., Yang, J., (2012) Development of high pressure gaseous hydrogen storage technologies, International Journal of Hydrogen Energy 37:1048 - 1057

[3] Régnier, N., Fontaine, S., (2001) Determination of the thermal degradation kinetic parameters of carbon fibre reinforced epoxy using TG. Journal of Thermal Analysis and Calorimetry 64:789 799. 
[4] Jiang, J., Pickering, S.J., Walker, G.S., Bowering, N., Wong, K.H., Rudd, C.D., (2007) Soft ionization analysis of evolved gas for oxidative decomposition of an epoxy resin/carbon fibre composite. Thermochimica Acta 454:109-115.

[5] Noël, D., Hechler, J.J., Cole, K.C., Chouliotis, A., Overbury, K.C., (1998) Quantitative thermal characterization of carbon-epoxy composites using differential scanning calorimetry and thermogravimetric analysis. Thermochimica Acta 125:191-208.

[6] Branca, C., Di Blasi, C., Galgano, A., Milella, E., (2011) Thermal and kinetic characterization of a toughened epoxy resin reinforced with carbon fibers. Thermochimica Acta 517:53-62

[7] Biswas, B., Kandola, B.K., Horrocks, A.R., Price, D., (2007) A quantitative study of carbon monoxide and carbon dioxide evolution during thermal degradation of flame retarded epoxy resins. Polymer Degradation and Stability 92:765-776.

[8] Hshieh, F.Y., Beeson, H.D., (1997) Flammability testing of flame-retarded epoxy composites and phenolic composites. Fire and Materials 21:41-49.

[9] Sorathia, U., Lyon, R., Gann, R.G., Gritzo, L., (1997) Materials and Fire Threat. Fire Technology 33 .

[10] Sorathia, U., Long, G., Gracik, T., Blum, M., Ness, J., (2001) Screening tests for fire safety of composites for marine applications. Fire and Materials 25:215-222.

[11] Mouritz, A.P., Mathys, Z., Gibson, A.G., (2006) Heat release of polymer composites in fire. Composites: Part A 37:1040-1054.

[12] Briggs, P.J., Hunter, J.G., "Macro-scale multi-component materials in fire". MMS16 PYROMMS Project: UK Department of Trade and Industry report CHJB/005/00055C, $8^{\text {th }}$ June 2004.

[13] Sorathia, U., Dapp, T., Kerr, J., "Flammability characteristics of composites for shipboard and submarine internal application", Proceeding of the $36^{\text {th }}$ International SAMPE symposium, 1991, pp. $1868-78$.

[14] Quang Dao, D., Luche, J., Richard, F., Rogaume, T., Bourhy-Weber, C., Ruban, S., (2013)

Determination of characteristic parameters for the thermal decomposition of epoxy resin/carbon fibre composites in cone calorimeters. International Journal of Hydrogen Energy 38(19):81678178, http://dx.doi.org/10.1016/j.ijhydene.2012.05.116

[15] Sorathia, U., "Flammability and fire safety of composite materials", Proceedings of the $1^{\text {st }}$ International Workshop on Composite Materials for Offshore Operations, 1993, pp. 309-317.

[16] Tewarson, A., Macaione, D.P., (1993) Polymers and composites - an examination of fire spread and generation of heat and fire products. Journal of Fire Sciences 11:421-441.

[17] Gibson, A.G., Hume, J., (1995) Fire performance of composite panels for large marine structures. Plastics, Rubbers \& Composites Processing and Applications 23:175-183.

[18] Sastri, S.B., Armistead, J.P., Keller, T.M., Sorathia, U., "Flammability characteristics of phthalonitrile composites", Proceedings of the $42^{\text {th }}$ International SAMPE Symposium, 1997, pp.1032-1038.

[19] Allison, D.M., Marchand, A.J., Morchat, R.M., (1991) Fire performance of composite materials in ships and offshore structures. Marine Structures 4:129-140.

[20] Mouritz, A.P., Gibson, A.G., Fire Properties of Polymer Composite Materials, Springer, 2006, p. 273.

[21] Sorathia, U., Beck, C., "Fire protection of glass/vinyl ester composites for structural applications", Proceedings of $41^{\text {st }}$ International SAMPE Symposium, 1996, pp. 687-697.

[22] Brown, J.R., Mathys, Z., Riddell, S.Z., Wake, L.V., (1995) Fire retardant performance of some surface coatings for naval ship interior applications. Fire \& Materials, 19: 109-118. 
[23] Sorathia, U., Gracik, T., Ness, J., Durkin, A., Williams, F., Hunstad, M., Berry, F., (2003) Evaluation of intumescent coating for shipboard fire protection. Journal of Fire Sciences, 21: 423450 .

[24] Tewarson, A., Macaione, D.P., (1993). Polymer and composites - an examination of fire spread and generation of heat and fire products, Journal of Fire Sciences 11: 421-441.

[25] Bourbigot, S., Duquesne, S., "Intumescence-Based Fire Retardants," Fire Retardancy of Polymeric Materials (2 ${ }^{\text {nd }}$ ed), Wilkie C.A., Morgan A.B. (ed.), CRC Press Taylor \& Francis Group, 2010, p. 129.

[26] Han, Z., Fina, A., Malucelli, G., Camino, G., (2010) Testing fire protective properties of intumescent coatings by in-line temperature measurements on a cone calorimeter, Progress in Organic Coatings, 69: 475-480

[27] Kandare, E., Griffin, G.J., Feih, S., Gibson, A.G., Lattimer, B.Y., Mouritz, A.P., (2012) Fire structural modeling of fibre - polymer laminates protected with an intumescent coating. Composites: Part A, 43: 793-802.

[28] Torre, L., Kenny, J.M., Maffezzoli, A.M., (1998) Degradation behaviour of a composite material for thermal protection systems. Part I - Experimental characterization. Journal of Materials Science, 33: $3137-3143$.

[29] Fateh, T., Rogaume, T., Luche, J., Richard, F., Jabouille, F., (2013) Kinetic and mechanism of the thermal degradation of a plywood by using thermogravimetry and Fourier transformed infrared spectroscopy analysis in nitrogen and air atmosphere. Fire Safety Journal, 58: 25 - 37.

[30] ISO 5660-1: 2002 (E). Reaction-to-fire tests - heat release, smoke production and mass loss rate Part 1: heat release rate (cone calorimeter method). Geneva, Switzerland: ISO; 2002.

[31] Luche, J., Mathis, E., Rogaume, T., Richard, F., Guillaume, E., (2012) High density polyethylene thermal degradation and gaseous compound evolution in a cone calorimeter. Fire Safety Journal, 54: $24-35$.

[32] Tewarson, A., "Generation of heat and gaseous, liquid, and solid products in fires," The SFPE Handbook of Fire Protection Engineering ( $4^{\text {th }} e d$.), National Fire Protection Association, 2008, p. $3-109$.

[33] Scudamore, M.J., Briggs, P.J., Prager, F.H., Cone calorimetry - A review of tests carried out on plastics for the Association of Plastics Manufacturers in Europe. Fire and Materials, 1991, 15: 65 -84 .

[34] Ruban, S., Heudier, L., Jamois, D., Proust, C., Bustamante-Valencia, L., Jallais, S., KremerKnobloch, K., Maugy, C., Villalonga, S., (2012) Fire risk on high-pressure full composite cylinders for automotive applications. International Journal of Hydrogen Energy, 37: $17630-$ 17638.

[35] Tsai, K.C., (2009) Orientation effect on cone calorimeter test results to assess fire hazard of materials. Journal of Hazardous materials, 172: $763-773$ 